\title{
Differences in Coping with Stressful Situations Between Tanzanian and Emirati University Students
}

\author{
Abdullah Seif Abdullah and Abdalla A. R. M. Hamid* \\ Department of Psychology and Counseling, United Arab Emirates University, PO Box 17771, Al Ain, United Arab Emirates
}

\begin{abstract}
This study was an attempt to examine and identify the coping dimensions of Tanzanian and UAE university students. A sample of 233 students was randomly selected from each of the two countries and the Coping Inventory for Stressful Situations (CISS) was used to assess their coping. Principal component analysis with varimax rotation was used to identify the coping dimensions of the two groups. Results showed significant variations in coping within and between the two samples. In addition, considerable differences between the two samples were found in relation to age, gender, and marital status. The results were further discussed in relation to previous findings, limitations were highlighted and future research considerations were recommended.
\end{abstract}

\section{Introduction}

Coping with stressful situations has attracted tremendous interest of many researchers due to its importance in understanding human behavior. Based on the literature, there are diverse models of coping with stressful situations such as the transactional model [1], selfregulated learning model [2], and the tripartite model [3]. The transactional model is an appraisal based coping which postulates that individual's cognitive appraisal and coping processes are influenced interactively by a combination of personality-based and situational factors [4]. The self-regulated model refers to individual's capacity to understand one's emotions and their expressions [2]. The tripartite model defines coping as a temperamental approach of dealing with anxiety and depression [5]. However, the current research focuses on the transactional model as it proves to be more reliable with more consistent factor structure [6].

The transactional model of stress defines coping as gradually changing behavioral and cognitive attempts to deal with internal or external demands that are evaluated by the person as exceeding or taxing his/her resources $[1,7]$.

A number of theories categorized strategies related to coping with stressful situations. These theories are based on research conducted in different settings. Yet, coping theories and models do generally share the following three features [6]: theories mainly postulate two to three coping dimensions; tools developed to gauge these factors are overlapping in content; and, with exception to the Coping Inventory for Stressful Situations, coping measures lack reliability and satisfactory factor structure.

Lazarus and Folkman recognized eight ways of coping with stress which reflect two techniques of coping, namely, emotion-oriented coping and task-oriented coping. The eight ways of coping are; selfcontrol, positive appraisal, confrontive coping, planful problem solving, escape-avoidance, seeking social support, distancing, and accepting responsibility [7]. There are several theoretical models and instruments related to coping $[8,9]$ and the number of coping strategies is potentially infinite because every person can develop his/her own particular methods to cope with stress, although through social learning people acquire a few culturally-based ways of overcoming stress [10].

McCrae and Costa [11] suggested two types of coping; neurotic coping and mature coping. They defined mature (problem focused) coping as dealing with changing something in the situation and acting directly in order to remove the source of stress. Whereas, neurotic (emotion focused) coping aims at reducing or managing the emotional distress associated with the situation rather than dealing with the situation itself [10]. There is a third type of coping, avoidance, which entails distancing self from the situation either through socializing with others or engaging in distracting activities $[6,12]$.

The Coping Styles Questionnaire [13] identified five modes of coping; active-cognitive, active behavioral, avoidance, problem focused and emotion focused coping. The Coping Orientation to the Problem Experience (COPE) describes 15 different coping modalities through the use of orthogonal Component factor analysis [10]. Endler and Parker's Coping Inventory for Stressful Situations (CISS) suggests three dimensions of coping namely: avoidance-focused, emotionfocused, and problem-focused coping [6,13]. Later, researchers such as Cosway et al. [7] and Rafnsson et al. [6] identified four dimensions of coping that replicate Endler and Parker's findings, but the avoidance coping was split into two dimensions: distraction and social diversion. The three factors of CISS scale assessing task, emotion, and avoidance oriented coping are the most robust dimensions identified in the general coping literature [14].

Gender differences in coping strategies were also reported in the literature in which the factor structure remained stable, nonetheless, women were reported to score higher in emotion and avoidance oriented coping styles [6]. The Coping Inventory for Stressful situation (CISS) has replicable factors in both the three and the four factor representations. However, a noteworthy fact is that Endler and parker used exploratory PCA in their analysis but when confirmatory factor analysis (CFA) was applied the four factor model showed better model fit [14].

The other shared feature among coping inventories is the limitation of unsatisfactory psychometric properties such as unstable factor

"Corresponding Author: Dr. Abdalla A. R. M. Hamid, Deparment of Psychology and Counseling, United Arab Emirates University, PO Box 17771, Al Ain, United Arab Emirates, Tel: +971 3 7136477; E-mail: ahamid@uaeu.ac.ae

Citation: Abdullah AS, Hamid A (2015) Differences in Coping with Stressful Situations Between Tanzanian and Emirati University Students. Int J Psychol Behav Anal 1: 108. doi: http://dx.doi.org/10.15344/2455-3867/2015/108

Copyright: (c) 2015 Abdullah et al. This is an open-access article distributed under the terms of the Creative Commons Attribution License, which permits unrestricted use, distribution, and reproduction in any medium, provided the original author and source are credited. 
structure and low reliability [9]. This weakness may be caused by cultural differences. Rafnson, et al. [6] suggested that future studies should investigate the replication of CISS factor in different cultures. Literature has shown that there are limited studies that focus on cultural differences in coping Sica, et al. [10] compared the coping strategies between Italian and American university students using Coping Orientations to Problems Experienced (COPE). Their findings indicated differences between the two groups and, thus, concluded that cultural differences may have played some role in determining the results of factor analysis as Europeans may probably use less rational coping than North Americans. Therefore, the present study is a cross-cultural validation that attempts to identify and compare the coping strategies for stressful situation used by Tanzanian and UAE university students. We postulated that there are differences in coping strategies between Tanzanians and Emirati undergraduate samples.

\section{Methods}

\section{Participants}

The participants were drawn from two independent populations, United Arab Emirates (UAE) and Tanzania. The UAE University was selected in UAE as it encompasses students from all over the UAE Emirates. On the other side, the Zanzibar Tunguu University was selected in Tanzania. Zanzibar was particularly selected as it shares with UAE the predominantly Islamic culture. Participants were selected using random sampling technique. Sample 1 was composed of 197 undergraduate students studying at United Arab Emirates University. There were 39.1\% ( $\mathrm{n}=77)$ male and $60.9 \%(\mathrm{n}=120)$ female participants of whom $86.3 \%(n=170)$ were single, $13.7 \%(n=27)$ married. The UAE participants age ranged between 17 and 26 years (Mean age $=20.56, \mathrm{SD}=1.58)$. About $23.9 \%(\mathrm{n}=47)$ were in first year, $18.8 \%(n=37)$ second year, $29.9 \%(n=59)$ third year, $27.4 \%(n=54)$ in their fourth year.

Sample 2 was composed of 197 undergraduate students studying at Tunguu University in Tanzania. There were $42.1 \% \quad(n=83)$ male and 57. $9 \%(n=114)$ female participants of whom $81.2 \%(n=160)$ were single and $18.8 \%(n=37)$ were married. The Tanzanian participants age ranged between 17 and 27 years (Mean age $=23.1, \mathrm{SD}=2.15$ ) About 31.5\% ( $n=62)$ were in first year, $26.4 \%(n=52)$ second year, $26.4 \%(n=52)$ third year, and $15.7 \%(n=31)$ were in fourth year.

\section{Instrument and procedure}

Research data were collected using the Coping Inventory for Stressful Situations (CISS) by Endler and Parker [15]. The Arabic version of CISS, validated by Hamid and Musa was used among UAE students. Data from the UAE sample was analyzed to identify its internal consistency. Data showed higher internal reliability as indicated by Chrobach alpha $\mathrm{r}=.85(\mathrm{M}=156.08, \mathrm{SD}=18.12)$. The Tanzanian sample responded to a translated CISS version into Kiswahili, which is the Tanzanian national language. The Kiswahili version went through a translation-back-translation procedure to maintain the items semantic equivalence (SE) of a translated measure. Subsequently, the procedures suggested by Mallinckrodt and Wang were applied in translating the Scale. The CISS comprises 48 items that are distributed in three major factors namely; task-oriented, emotionoriented, and avoidance coping. Each factor consists of 16 items. Individuals who score high on task-oriented coping use behavioral or cognitive problem-solving techniques when threatened with stress. Those who use emotion-oriented coping respond to stressful situations with emotional outbursts, self-preoccupation, or fantasy. Users of avoidance coping rely on social support or distract themselves with other activities [6]. The Data from the Tanzanian sample showed an acceptable reliability, $\mathrm{r}=.74(\mathrm{M}=159.58, \mathrm{SD}=17.22)$.

A front page was attached to the questionnaire (CISS) requesting the participants consent after explaining the goal of the research followed by some demographic information such as nationality, age, gender, year in the college, and marital status.

Pearson product-moment correlation was used to examine relationships between age and coping dimensions. T-test was used to identify gender and marital status differences in coping within each sample. Finally, one way ANOVA was employed to identify coping differences in relation to year of study at the university.

\section{Construct validity of the CISS}

Data were factor analyzed using principal component analysis with varimax rotation to identify the underlying coping factors of Tanzanian and UAE students as per data collected in this study. The literature indicates that the CISS contains three main coping factors $[6,12]$. McWilliams, et al. asserted that if factor structures are not similar across samples meaningful comparisons across groups on these factors or subscales are prohibited. The three factor model consists of the most robust dimensions identified in the general coping literature [14]. The results showed that both the UAE data and the Tanzania data replicated the three-factor model. Table 1 shows the factor loadings for three factor model of the UAE sample. Data from the two samples were analyzed separately because of different number of items in corresponding factors.

When using the UAE sample, from the 48 items (as indicated in Table 1) three factors were extracted with the Eigenvalues greater than 1.00 which is the accepted level as a criterion for a valid factor [16]. All the items loaded in their respective dimensions except for item 34 (originally emotion-oriented) and item 35 (originally avoidance) which both loaded on the task-oriented factor. Hence, 16 items loaded in task-oriented factor, 15 items in emotion-oriented factor, and 15 in avoidance factor.

On the other hand, 11 items loaded in task oriented factor in the Tanzania sample, 6 in emotion coping, and nine (9) items in avoidance oriented factor as shown in Table 2. The items that loaded wrongly are 3 items from the task -oriented coping (item no 10, 15, and 46), 8 items from the emotion-oriented coping $(13,14,28,30,33$, 34,38 , and 45), and 6 items from the avoidance coping (3, 4, 9, 18, 20,23 , and 35 ). One item (item 10) from task oriented factor did not load significantly anywhere, and the same case applies to 2 items from emotion-oriented factor (16 and 22).

\section{Results}

\section{Results of United Arab Emirates sample}

Pearson correlation analysis yielded no significant correlation between age and coping dimensions (problem-focused, emotionfocused, and avoidance). However, t-test results revealed significant gender differences in avoidance coping $(t=2.31, d f=$ 231, $\mathrm{p}<.05)$. Male UAE students reported more use of avoidance coping compared to female students (Table 3). Cohen's d was used as an estimate of effect size for t-test [17] the effect size was 
Citation: Abdullah AS, Hamid A (2015) Differences in Coping with Stressful Situations Between Tanzanian and Emirati University Students. Int J Psychol Behav Anal 1: 108. doi: http://dx.doi.org/10.15344/2455-3867/2015/108

Page 3 of 5

\begin{tabular}{|c|c|c|c|c|}
\hline No & Items & Task & Emotion & Avoidance \\
\hline 1 & COP1 & .48 & & \\
\hline 2 & $\mathrm{COP} 2$ & .63 & & \\
\hline 3 & $\mathrm{COP} 3$ & & & .40 \\
\hline 4 & $\mathrm{COP} 4$ & & & .47 \\
\hline 5 & COP5 & & .45 & \\
\hline 6 & COP6 & .55 & & \\
\hline 7 & COP7 & & .54 & \\
\hline 8 & COP8 & & .48 & \\
\hline 9 & COP9 & & & .54 \\
\hline 10 & COP10 & .64 & & \\
\hline 11 & COP11 & & & .30 \\
\hline 12 & COP12 & & & .57 \\
\hline 13 & COP13 & & .63 & \\
\hline 14 & COP14 & & .68 & \\
\hline 15 & COP15 & .57 & & \\
\hline 16 & COP16 & & .48 & \\
\hline 17 & COP17 & & .76 & \\
\hline 18 & COP18 & & & .67 \\
\hline 19 & COP19 & & .62 & \\
\hline 20 & COP20 & & & .68 \\
\hline 21 & COP21 & .64 & & \\
\hline 22 & COP22 & & .58 & \\
\hline 23 & COP23 & & & .66 \\
\hline 24 & COP24 & .73 & & \\
\hline 25 & COP25 & & .65 & \\
\hline 26 & COP26 & .61 & & \\
\hline 27 & COP27 & .68 & & \\
\hline 28 & COP28 & & .52 & \\
\hline 29 & COP29 & & & .67 \\
\hline 30 & COP30 & & .60 & \\
\hline 31 & COP31 & & & .55 \\
\hline 32 & COP32 & & & .58 \\
\hline 33 & COP33 & & .35 & \\
\hline 34 & COP34 & .52 & & \\
\hline 35 & COP35 & .37 & & \\
\hline 36 & COP36 & .62 & & \\
\hline 37 & COP37 & & & .48 \\
\hline 38 & COP38 & & .54 & \\
\hline 39 & COP39 & .66 & & \\
\hline 40 & COP40 & & & .50 \\
\hline 41 & COP41 & .65 & & \\
\hline 42 & COP42 & .65 & & \\
\hline 43 & $\mathrm{COP} 43$ & .71 & & \\
\hline 44 & COP44 & & & .30 \\
\hline 45 & COP45 & & .37 & \\
\hline 46 & COP46 & .47 & & \\
\hline 47 & COP47 & .57 & & \\
\hline 48 & COP48 & & & .51 \\
\hline
\end{tabular}

\begin{tabular}{|c|c|c|c|c|}
\hline No & Items & Task & Emotion & Avoidance \\
\hline 1 & COP1 & .37 & & \\
\hline 2 & COP2 & .49 & & \\
\hline 3 & $\mathrm{COP} 3$ & & .40 & \\
\hline 4 & $\mathrm{COP} 4$ & .44 & & \\
\hline 5 & COP5 & & .43 & \\
\hline 6 & COP6 & .45 & & \\
\hline 7 & COP7 & & .51 & \\
\hline 8 & COP8 & & .56 & \\
\hline 9 & COP9 & & .39 & \\
\hline 10 & COP10 & & .30 & \\
\hline 11 & COP11 & & & .31 \\
\hline 12 & COP12 & & & .47 \\
\hline 13 & COP13 & & & .44 \\
\hline 14 & COP14 & & & .45 \\
\hline 15 & COP15 & & & .31 \\
\hline 16 & COP16 & & & \\
\hline 17 & COP17 & & .40 & \\
\hline 18 & COP18 & & .34 & \\
\hline 19 & COP19 & & .54 & \\
\hline 20 & COP20 & .37 & & \\
\hline 21 & COP21 & .36 & & \\
\hline 22 & COP22 & & & \\
\hline 23 & COP23 & & .41 & \\
\hline 24 & COP24 & .33 & & \\
\hline 25 & COP25 & & .39 & \\
\hline 26 & COP26 & .43 & & \\
\hline 27 & COP27 & .41 & & \\
\hline 28 & COP28 & & & .35 \\
\hline 29 & COP29 & & & .43 \\
\hline 30 & COP30 & & & .32 \\
\hline 31 & COP31 & & & .32 \\
\hline 32 & COP32 & & & .31 \\
\hline 33 & COP33 & .40 & & \\
\hline 34 & COP34 & .34 & & \\
\hline 35 & COP35 & .44 & & \\
\hline 36 & COP36 & .43 & & \\
\hline 37 & COP37 & & & .40 \\
\hline 38 & COP38 & & & .34 \\
\hline 39 & COP39 & & & \\
\hline 40 & COP40 & & & .30 \\
\hline 41 & COP41 & .39 & & \\
\hline 42 & COP42 & .39 & & \\
\hline 43 & COP43 & .40 & & \\
\hline 44 & COP44 & & & .31 \\
\hline 45 & COP45 & & & .32 \\
\hline 46 & COP46 & & & .39 \\
\hline 47 & COP47 & & & \\
\hline 48 & COP48 & & & .33 \\
\hline
\end{tabular}

Table 2: The items' factor loadings for CSSI using Tanzanian sample. 
between small and medium (Table 3). No other significant gender differences were found in coping dimensions. Further, there were no significant differences between married and unmarried or between Emirati and non-Emirati students in coping. Furthermore, ANOVA analysis revealed no significant differences in coping in relation to year of study at the university.

\section{Results of Tanzanian sample}

Pearson correlation results showed that age was significantly related to avoidance coping $(\mathrm{r}=1.41, \mathrm{p}<.05)$. Older student reported more use of avoidance but age was not significantly related to problemfocused and emotion-focused coping.

T-test indicated significant gender differences in emotion-focused and avoidance coping $(\mathrm{t}=2.76, \mathrm{df}=231, \mathrm{p}<.01 ; \mathrm{t}=1.97, \mathrm{df}=231, \mathrm{p}<$ .05 , respectively). Female Tanzanian students reported higher rates of emotion-focused and avoidance coping compared to male students (Table 3). Significant difference in avoidance coping was found between married and unmarried Tanzanian students $(\mathrm{t}=2.09, \mathrm{df}=$ $231, p<.05)$. All effect size estimates were within the range of small to medium (Table 3). Married students reported more use of avoidance coping compared to the unmarried (Table 3). There were no other significant differences in coping with reference to marital status. ANOVA results showed significant differences only in avoidance coping between students in different years of study at the university $(\mathrm{F}=3.93, \mathrm{df}=3,229, \mathrm{p}<.01)$. Partial eta squired was used to assess effect size estimates for analysis of variance. The results showed that the effect size estimate was small $\left(\eta_{\mathrm{p}}^{2}=0.05\right)$. sample, married participants from Tanzania significantly reported more use of avoidance coping compared to their unmarried counterparts. However, these results did not support the previous findings by Amirkhan and Auyeung [19] where unmarried participant were found to use more avoidance coping than the married ones.

As noticed from the results, male UAE participants reported significantly greater use of avoidance coping compared to female students while no gender differences in emotion-focused and taskfocused coping were reported. On the other hand, female Tanzanian students reported higher rates of emotion-focused and avoidance coping compared to male Tanzanian students. The results of the UAE sample were inconsistent while the results of Tanzanian sample were consistent with finding of many previous studies. For instance, Cosway et al. [7] found that female participants reported significantly higher scores than male participants on emotion-oriented and avoidance coping, while male participants scored higher on task oriented coping. Furthermore, Rafnsson et al. [6] found that female participants scored significantly higher than male participant on emotion-oriented and avoidance coping. Cash, Santos, \& Williams [20] also found that women significantly used more avoidance than men. However, Cosway et al. [7] mentioned that gender differences in coping are not consistent across studies.

The different patterns of coping used by UAE and Tanzanian samples in relation to age, gender, and marital status may reflect cultural variations in coping dimensions employed by different categories of individuals from the two countries to deal with stressful demands. It could be possible that such differences are shaped by

\begin{tabular}{|c|c|c|c|c|c|c|c|}
\hline \multirow[t]{2}{*}{ Variable } & & \multicolumn{2}{|c|}{ Avoidance } & & \multicolumn{2}{|c|}{ Emotion-focused } & \multirow[b]{2}{*}{ Effect size Cohen's $d$} \\
\hline & & Mean & SD & Effect size Cohen's $d$ & Mean & $\mathrm{SD}$ & \\
\hline \multirow[t]{2}{*}{ UAE Sample } & Male & 47.36 & 8.35 & 0.31 & - & - & \\
\hline & Female & 44.52 & 9.73 & & - & - & \\
\hline \multirow[t]{4}{*}{ Tanzanian Sample } & Male & 28.68 & 5.34 & 0.44 & 17.76 & 4.83 & $0.36(\mathrm{p}<.05)$ \\
\hline & Female & 30.91 & 4.90 & & 19.46 & 4.49 & \\
\hline & Married & 30.82 & 5.18 & 0.30 & - & - & \\
\hline & Unmarried & 29.30 & 5.03 & & - & - & \\
\hline
\end{tabular}

\section{Discussion}

The findings of the present study suggested that age was significantly related to avoidance coping among Tanzanian sample while it was not related to coping in UAE sample. Older Tanzanian students reported more use of avoidance, the older the age, the more the use of avoidance coping. This finding (of Tanzanian sample) was consistent with Field and Primz [18] study in which they found that older participants tended to use more cognitive avoidance coping compared to the younger ones. However, age was not found to relate significantly to problem-focused and emotion-focused coping among Tanzanians. The disparity in coping dimensions between Tanzanian and UAE samples may be interpreted as cultural differences as culture plays a vital role in how its people will cope with different stressful situations. They may also be influenced by the demographic differences between the two samples. Further, these findings provide additional support for applicability of CISS to coping research across cultures [6].

The results of the UAE Sample and the Tanzanian sample regarding marital status differences in coping were consistent except for avoidance coping. While no significant coping differences were reported between married and unmarried participant in the UAE cultural influences. Older and married Tanzanians may tend to use avoidance coping as an indication of wisdom, or socialize with others as a means of coping with different stressors. It is also possible that results might have been confounded with other variables such as demographic variables or number of items in each dimension. Further investigation needs to be conducted to identify possible cultural influences on coping.

\section{Limitations and Implications for Future Research}

The findings of this study are promising, yet, there are some limitations that may need to be ironed out in future studies in order to improve the quality of research findings. First, the language used to test the coping dimensions in the two samples was different. In UAE sample, the research used the Arabic version of CISS where Arabic is the native language. In contrary, the Kiswahili version of the CISS was used among Tanzanians since Kiswahili is their native language. There is a possibility that the findings were in some way influenced by language differences between the two samples. Second, the study was cross-cultural in nature, therefore, the cultural differences between the two groups could influence dimensions used to handle stressful 
Citation: Abdullah AS, Hamid A (2015) Differences in Coping with Stressful Situations Between Tanzanian and Emirati University Students. Int J Psychol Behav Anal 1: 108. doi: http://dx.doi.org/10.15344/2455-3867/2015/108

Page 5 of 5

situations. Hence, cultural factors need to be well addressed in order to make a sound comparison. There is also a possibility that the results may be influenced by demographic factors. We need to be cautious in generalizing the current findings because students at Tunguu University mainly came from Zanzibar and do not appropriately represent the whole Tanzanian population. Third, the former argument may also suggest improvement in sampling procedures so that the two cultures will be properly represented. These limitations suggest a number of directions for further exploration of dimensionality of CISS across cultures. The current researchers suggest that more sophisticated approaches such as Confirmatory factor Analysis may be used in the future research in order to offer more precise factors compared to the principal component analysis applied in the current study. Based on the inconsistency of some findings across research literature, the current researchers suggest that the CISS factor structure need to be replicated in more cross-cultural studies in order to establish its factor structure in many more cultural settings. There may be cultural differences in coping between the western and nonwestern cultures. These phenomena may call for more comparisons of coping among various cultural settings such as western and nonwestern coping dimensionality as Western culture is more individualistic in nature while the Eastern and other African cultures are more collectivist cultures.

\section{Competing Interests}

The author declare that he has no competing interests.

\section{Author Contributions}

Both the authors substantially contributed to the study conception and design as well as the acquisition and interpretation of the data and drafting the manuscript.

\section{References}

1. Lazuras RS, Folkman S (1984) Stress, appraisal and coping. New York, NY: Springer.

2. Boekaerts $M$ (2006) Self-regulation and effort investment. In Sigel E and Renninger KA (Eds.) Handbook of Child Psychology, Vol. 4, Child Psychology in Practice Hoboken, NJ: Wiley, (p. 345-377).

3. Clark LA, Watson D (1991) Tripartite Model of anxiety and depression: Psychometric evidence and taxonomic implications. J Abnorm Psycho 100: 316-336.

4. Duhachek A, Kelting K (2009) Coping repertoire: integrating a new conceptualization of coping with transactional theory. Journal of consumer Psychology 19: 473-485.

5. Fox JK, Halpern LF, Ryan JL, Lowe KA (2010) Stressful life events and the tripartite model: relations to anxiety and depression in adolescent females. J Adolesc 33: 43-54.

6. Rafnsson FD, Smari J, Winde M, Mears SA, Endler NS (2006) Factor structure and psychometric characteristics of the Icelandic version of the Coping Inventory for Stressful Situations (CISS). Personality and Individual Differences 40: 1247-1258.

7. Cosway R, Endler NS, Sadler AJ, Deary IJ (2000) The Coping Inventory for Stressful Situations: Factor structure and associations with personality traits and psychological heath. Journal of Applied Behavioral Research 5 : 121-143

8. Parker JDA, Endler NS (1996) Coping and defense: An historical overview. In M Zeidner \& N. S. Endler (Eds.), Handbook of coping: Therapy, research, applications (p3-23), New York, NY: John Wiley \&Sons.

9. Skinner EA, Edge K, Altman J, Sherwood H (2003) Searching for the structure of coping: a review and critique of category systems for classifying ways of coping. Psychol Bull 129: 216-269.
10. Sica C, Novara C, Dorz S, Sanavio E (1997) Coping strategies: evidence for cross- cultural differences. A preliminary study with the Italian version of coping orientation to problem experienced (COPE). Journal of Personality and Individual Differences 23: 1025-1029.

11. McCrae RR, Costa PT (1986) Personality, coping, and coping effectiveness in an adult sample. Journal of Personality 54: 385-405.

12. Wonderlich-Tierney AL, Vander Wal JS (2010) The effects of social support and coping on the relationship between social anxiety and eating disorders. Eat Behav 11: 85-91.

13. Billings AG, Moos RH (1981) The role of coping responses and social resources in attenuating the stress of life events. J Behav Med 4: 139-157.

14. McWilliams LA, Cox BJ, Enns MW (2003) Use of the coping inventory for stressful situations in a clinically depressed sample: factor structure, personality correlates, and prediction of distress. J Clin Psychol 59: 423437.

15. Endler NS, Parker JD (1990) Coping Inventory for Stressful Situations (CISS): Manual. Toronto: Multi-Health System.

16. Green SB, Salkind NJ, Akey TM (2000) Using SPSS for Windows, (2nd Edition), Prentice Hall, Upper saddle River, NJ.

17. Howell DC (1997) Statistical Methods for Psychology. Belmont: Duxbury.

18. Fields L, Prinz RJ (1997) Coping and adjustment during childhood and adolescence. Clin Psychol Rev 17: 937-976.

19. Amirkhan J, Auyeung B (2007) Coping with stress across the lifespan: Absolute vs. relative changes in strategy. Journal of Applied Developmental Psychology 28: 298-317.

20. Cash TF, Santos MT, Williams EF (2005) Coping with body-image threats and challenges: validation of the Body Image Coping Strategies Inventory. J Psychosom Res 58: 190-199. 